\title{
Visão atual da hemocromatose hereditária
}

\section{Current approach to hereditary hemochromatosis}

Rodolfo Delfini Cançadol

Carlos Sérgio Chiattone ${ }^{2}$

\begin{abstract}
A hemocromatose hereditária (HH) está relacionada a diversos distúrbios do metabolismo do ferro que ocasionam sua sobrecarga tecidual. A HH clássica está associada às mutações do gene HFE (homozigose para C282Y ou duplo heterozigose para C282Y/H63D), sendo encontrada quase exclusivamente em descendentes do norte Europeu. A hemocromatose hereditária, quando não relacionada ao gene HFE, é causada por mutações de outros genes, recentemente identificados, envolvidos no metabolismo do ferro. Hepcedina é o hormônio regulador do ferro que inibe a ferroportina, proteina exportadora de ferro dos enterócitos e dos macrófagos; um defeito na expressão do gene da hepcedina ou na sua função costuma ser a causa da maioria dos tipos de hemocromatose hereditária. Os alvos acometidos pela HH são órgãos e tecidos - fígado, coração, pâncreas, articulações e pele-, sendo a cirrose e o diabetes melito os sinais tardios da doença em pacientes com expressivo aumento da concentração hepática de ferro. Pacientes com diagnóstico estabelecido de hemocromatose hereditária e sobrecarga de ferro devem ser tratados com flebotomia para a obtenção de depleção do ferro do organismo; em seguida, com flebotomia de manutenção. As causas mais frequentes de morte por hemocromatose hereditária são câncer hepático, cirrose, miocardiopatia e diabete; entretanto, pacientes submetidos à depleção do ferro de maneira satisfatória e antes do desenvolvimento da cirrose ou da diabete podem ter sobrevida normal.
\end{abstract}

Descritores: Deficiência de ferro/metabolismo; Sobrecarga de ferro; Hemocromatose Igenética; Hemocromatose/congênito; Flebotomia

\section{Introdução}

O ferro é um elemento essencial na maioria dos processos fisiológicos do organismo humano, desempenhando função central no metabolismo energético celular. Sua quantidade total, no adulto, é de aproximadamente 3,5 a $4 \mathrm{~g}$; a maior parte (de 1,5 a 3,0 g) está ligada ao heme da hemoglobina e tem como principal função a oxigenação dos tecidos, e outra parte está armazenada sob a forma de ferritina ou de hemossiderina nas células do sistema mononuclear fagocitário, principalmente no fígado, na medula óssea e no baço.(1) Fisiologicamente, o organismo não é capaz de aumentar a excreção de ferro, mesmo quando há sobrecarga dele; portanto, o aumento progressivo do aporte de ferro, por via gastrointestinal ou parenteral, leva impreterivelmente à condição patológica de sobrecarga de ferro. ${ }^{(1-4)}$

O quadro 1 mostra as principais síndromes clínicas que podem resultar em acúmulo de ferro. O quadro 2 descreve as

\footnotetext{
${ }^{I}$ Serviço de Hematologia e Hemoterapia, Faculdade de Ciências Médicas da Santa Casa de São Paulo - FCMSCSP - São Paulo (SP), Brasil. ${ }^{2}$ Disciplina de Hematologia e Oncologia, Faculdade de Ciências Médicas da Santa Casa de São Paulo - FCMSCSP - São Paulo (SP), Brasil.
}

Conflito de interesse: sem conflito de interesse

Recebido: $3 / 8 / 2009$

Aceito: $8 / 12 / 2009$

Correspondência: Rodolfo Delfini Cançado Hemocentro da Santa Casa de São Paulo Rua Marquês de Itu, $579-3^{\circ}$ andar 01223-001 - São Paulo (SP), Brasil Tel.: (55 11) 2176-7255

E-mail:rdcan@uol.com.br 
características genéticas e clínicas das principais síndromes clínicas relacionadas à hemocromatose hereditária.

\section{Hemocromatose hereditária $(\mathrm{HH})$}

No início do século XIX, Trousseau e Troisier descreveram a síndrome clínica caracterizada por cirrose hepática, diabetes melito e hiperpigmentação da pele, constatando que era causada por acúmulo de ferro em diferentes órgãos; no entanto, somente em 1889 foi denominada, por Von Recklinghausen, de "hemocromatose" (do grego haima = sangue e chromatos $=$ cor $).^{(1,4)}$

Em 1996, um grupo de pesquisadores americanos identificou, no braço curto do cromossomo 6 , o gene da hemocromatose pertencente ao complexo principal de histo- compatibilidade; ele foi inicialmente denominado de HLA-H ( $\mathrm{H}$ de hemocromatose), e, posteriormente, de gene HFE (classical hereditary hemochromatosis). ${ }^{(1,4)}$

A HH é uma doença autossômica recessiva, associada, na maioria das vezes, à mutação do gene HFE, e está caracterizada pelo aumento inapropriado da absorção intestinal de ferro, com consequente acúmulo progressivo desse íon em diferentes órgãos e tecidos, especialmente fígado, coração, pâncreas, pele e articulações, podendo ocasionar lesão celular e tecidual, fibrose e insuficiência funcional. ${ }^{(3,5)}$

\section{Epidemiologia}

Estudos populacionais indicam que a $\mathrm{HH}$ teve origem no norte europeu, em populações de origem nórdica ou celta.
Quadro 1. Principais síndromes clínicas relacionadas à sobrecarga de ferro ${ }^{(1-4)}$

\begin{tabular}{|c|c|}
\hline $\begin{array}{l}\text { 1. Primária } \\
\text { a. HH - gene HFE (Tipo 1) } \\
\text { b. HH - Juvenil (Tipo 2) } \\
\text { Hemojuvelina (Tipo 2A) } \\
\text { Hepcedina (Tipo 2B) } \\
\text { c. HH - gene do Receptor } 2 \text { da Transferrina (Tipo 3) } \\
\text { d. HH - gene da Ferroportina (Tipo 4) } \\
\text { e. Outros tipos: } \\
\text { HH - gene da cadeia pesada da Ferritina } \\
\text { Aceruloplasminemia } \\
\text { Mutação DMT1 (HH neonatal) } \\
\text { Atransferrinemia } \\
\text { Ataxia de Friedreich }\end{array}$ & $\begin{array}{l}\text { 2. Secundária } \\
\text { 2.1 Transfusional } \\
\text { a. Anemia hemolítica crônica } \\
\text { - talassemias, doença falciforme } \\
\text { b. Síndrome mielodisplásica } \\
\text { c. Anemia aplástica } \\
\text { d. Anemia de Fanconi } \\
\text { e. Anemia Backfan Diamond } \\
\text { 2.2 Não transfusional } \\
\text { f. Doença hepática crônica } \\
\text { - hepatite viral (vírus B, C) } \\
\text { - hepatite induzida por etanol } \\
\text { - síndrome metabólica } \\
\text { - esteatohepatite não alcoólica } \\
\text { g. Porfíria cutânea tarda } \\
\text { h. Shunt porto-cava } \\
\text { i. Sobrecarga africana de ferro } \\
\text { j. Iatrogênica }\end{array}$ \\
\hline
\end{tabular}

A mutação C282Y do gene HFE é mais frequente em indivíduos caucasianos do noroeste da Europa, da América do Norte, da Austrália e da Nova Zelândia; na Europa oriental e meridional, na África do Norte e no Oriente Médio, sua frequência é intermediária, e, em populações asiáticas, africanas ou afrodescendentes das Américas Central e do Sul, raramente é encontrada. ${ }^{(6)}$

Estudos envolvendo populações dos Estados Unidos da América, da Austrália e da Europa demonstraram que a frequência de homozigotos e heterozigotos para a mutação $\mathrm{C} 282 \mathrm{Y}$ varia entre $0,2 \% \mathrm{e}$ $0,7 \%$, e entre $7 \%$ e $14 \%$, respectivamente. Amutação H63D do gene HFE

HH - Hemocromatose hereditária

Quadro 2. Características genéticas e clínicas das principais síndromes clínicas relacionadas à hemocromatose hereditária (1-3)

\begin{tabular}{|c|c|c|c|c|c|}
\hline Doença Genética & Gene & Cromossomo & Transmissão & $\begin{array}{l}\text { Início da clínica } \\
\text { (década) }\end{array}$ & $\begin{array}{l}\text { Principal alteração clínica } \\
\text { (curso clínico) }\end{array}$ \\
\hline HFE (HH tipo 1) & $\mathrm{HFE}$ & 6 & $\mathrm{AR}$ & $3^{a}-5^{a}$ & Hepática e articular (de leve a grave) \\
\hline $\begin{array}{l}\text { Hemojuvelina (HH tipo 2A) } \\
\text { Hepcedina (HH tipo 2B) }\end{array}$ & $\begin{array}{l}\text { HJV } \\
\text { HAMP }\end{array}$ & $\begin{array}{c}1 \\
19\end{array}$ & $\begin{array}{l}\mathrm{AR} \\
\mathrm{AR}\end{array}$ & $2^{a}-3^{a}$ & Cardíaca e endócrina (grave) \\
\hline Receptor ${ }_{2}$ da transferrina (HH tipo 3 ) & $\mathrm{TfR}_{2}$ & 7 & $\mathrm{AR}$ & $3^{a}-5^{a}$ & Hepática (de leve a grave) \\
\hline $\begin{array}{l}\text { Doença da ferroportina (HH tipo 4A) } \\
\text { Doença da ferroportina (HH tipo 4B) }\end{array}$ & SLC40A1 & 2 & $\mathrm{AD}$ & $4^{\mathrm{a}}-5^{\mathrm{a}}$ & $\begin{array}{c}\text { Rara (leve) } \\
\text { Hepática e articular (leve) }\end{array}$ \\
\hline A (hipo) - ceruloplasminemia & Ceruloplasmina & 3 & $\mathrm{AR}$ & $2^{a}-3^{a}$ & $\begin{array}{l}\text { Neurológica, hematológica e } \\
\text { endócrina (grave) }\end{array}$ \\
\hline A (hipo) - transferrinemia & Transferrina & 3 & $\mathrm{AR}$ & $1^{a}-2^{a}$ & Hematológica (grave) \\
\hline DMT1 (divalent metal transporter) & DMT1 & 12 & $\mathrm{AR}$ & $3^{a}-5^{a}$ & Hematológica e hepática (de leve a grave) \\
\hline
\end{tabular}

AR = Autossômica recessiva; $\mathrm{AD}=$ Autossômica dominante; Hepática $=$ hepatomegalia, elevação das aminotransferases; Articular = artralgia, artrite; Cardíaca = miocardiopatia, arritmia; Endócrina = diabete, hipogonadismo; Neurológica = degeneração retiniana, síndrome extrapiramidal ataxia cerebelar e demência; Hematológica = anemia microcítica com ferro sérico e saturação da transferrina diminuídos 
é duas ou três vezes mais frequente que a $\mathrm{C} 282 \mathrm{Y}$, e a prevalência de heterozigotos e homozigotos para esta mutação varia entre $15 \%$ e $40 \%$ e entre $2,5 \%$ e $3,6 \%$, respectivamente. A frequência do genótipo C282Y/H63D é de aproximadamente $2 \%{ }^{(6,7)}$

A frequência da mutação $\mathrm{C} 282 \mathrm{Y}$ do gene HFE é três a oito vezes menor em indivíduos brasileiros do que a observada em caucasoides do norte da Europa e, provavelmente, essa diferença deve-se à diversidade étnica da população brasileira. Já a frequência alélica da mutação H63D do gene HFE parece ser semelhante entre essas duas populações. A tabela 1 relaciona as frequências alélicas das mutações $\mathrm{C} 282 \mathrm{Y}$, H63D e S65C do gene HFE de cinco estudos brasileiros.

Tabela 1. Frequência alélica das mutações C282Y e H63D do gene HFE no Brasil $^{(8-12)}$

\begin{tabular}{|c|c|c|c|c|}
\hline \multirow{2}{*}{$\begin{array}{l}\text { Estudo, ano e } \\
\text { local }\end{array}$} & \multirow{2}{*}{$\begin{array}{c}\text { Cor da } \\
\text { pele }\end{array}$} & \multicolumn{3}{|c|}{ Frequência alélica (\%) } \\
\hline & & $\begin{array}{l}\text { Mutação } \\
\text { C282Y }\end{array}$ & $\begin{array}{l}\text { Mutação } \\
\text { H63D }\end{array}$ & $\begin{array}{l}\text { Mutação } \\
\text { S65C }\end{array}$ \\
\hline Agostinho et al ${ }^{(8)}, 1999$ & $\mathrm{~B}$ & $(1,4)$ & $(16,3)$ & \\
\hline Campinas $(*)$ & $\mathrm{P}$ & $(1,1)$ & $(7,5)$ & NR \\
\hline$(\mathrm{N}=227)$ & M & $(1,1)$ & $(1,1)$ & \\
\hline Calado et al. ${ }^{(9)}, 2000$ & & & & \\
\hline $\begin{array}{l}\text { Ribeirão Preto } \\
\qquad(\mathrm{N}=320)\end{array}$ & $\mathrm{B}+\mathrm{P}+\mathrm{M}$ & $(2,2)$ & $(14,3)$ & NR \\
\hline Pereira et al. ${ }^{(10)}, 2001$ & $\mathrm{~B}$ & $(3,7)$ & $(20,3)$ & \\
\hline São Paulo & $\mathrm{P}$ & $(0,5)$ & $(6,4)$ & NR \\
\hline$(\mathrm{N}=395)$ & M & $(0,7)$ & $(13,0)$ & \\
\hline Oliveira et al. ${ }^{(11)}, 2003$ & $\mathrm{~B}$ & $(1,4)$ & $(8,6)$ & $(0,6)$ \\
\hline $\begin{array}{l}\text { São Paulo } \\
(\mathrm{N}=148)\end{array}$ & $\mathrm{P}$ & $(0,0)$ & $(2,4)$ & $(0,3)$ \\
\hline $\begin{array}{c}\text { Terada et al. }{ }^{(12)}, 2009 \\
\text { São Paulo } \\
(\mathrm{N}=542)\end{array}$ & NR & $(2,1)$ & $(13,6)$ & $(0,6)$ \\
\hline
\end{tabular}

$\mathrm{N}=$ número de participantes em cada estudo; $\mathrm{B}=$ branco; $\mathrm{P}=$ preto; $\mathrm{M}=$ mulato; $\mathrm{NR}=$ não realizado; (*) único trabalho que estudou um grupo indígena e não encontrou nenhum individuo com mutação $\mathrm{C} 282 \mathrm{Y}$ ou $\mathrm{H} 63 \mathrm{D}$ do gene HFE

Quando são analisados os pacientes com diagnóstico de $\mathrm{HH}$, verifica-se que $60 \%$ a $100 \%$ deles são homozigotos para a mutação $\mathrm{C} 282 \mathrm{Y}$ do gene $\mathrm{HFE}$; entretanto, o número reduzido de indivíduos com diagnóstico $\mathrm{HH}$, frente à elevada frequência das mutações do gene HFE, chamou a atenção dos pesquisadores com relação à penetrância incompleta do gene mutante. Estima-se que menos de 50\% dos indivíduos homozigotos para a mutação C282Y desenvolverão evidência laboratorial e/ou clínica de sobrecarga de ferro. ${ }^{(13-16)}$

Além disso, a expressão clínica ou fenotípica dos indivíduos com mutação do gene HFE pode sofrer a influência de fatores genéticos, clínicos e ambientais, interferindo no metabolismo do ferro e ocasionando o agravamento do seu acúmulo e do curso clínico da doença. ${ }^{(1,3,4,14,17)}$

As principais condições desfavoráveis, capazes de contribuir para a progressão mais rápida da doença, são: ser do sexo masculino, consumir em excesso bebida alcoólica, estar infectado pelo vírus $\mathrm{B}$ ou $\mathrm{C}$ da hepatite, ter anemia hemolítica crônica (talassemia, anemia falciforme, esferocitose hereditária), consumir em excesso vitamina $\mathrm{C} \mathrm{e}$ medicamentos com ferro (ou administrar ferro por via parenteral), o aparecimento da Porfiria cutânea tarda e a mutação concomitante de outro gene envolvido no metabolismo do ferro. ${ }^{(1,3,4,14,17)}$

\section{Correlação entre genótipo e fenótipo}

O maior risco de sobrecarga de ferro está associado à homozigose para a mutação $\mathrm{C} 282 \mathrm{Y}$ do gene HFE, sendo intermediário o risco para os doentes com genótipo $\mathrm{C} 282 \mathrm{Y} /$ H63D ou H63D/H63D, e baixo para doentes com genótipo C282Y/WT e H63D/WT. ${ }^{(13-18)}$

Os indivíduos C282Y/WT, usualmente, não desenvolvem doença clínica, entretanto, aproximadamente de $1 \%$ a $15 \%$ dos doentes com esse genótipo desenvolvem o fenótipo de hemocromatose semelhante ao observado no doente C282Y/C282Y, sugerindo a coexistência de fatores clínicos ou genéticos adicionais, que podem influenciar a favor da hemocromatose. ${ }^{(13-18)}$

As mutações H63D e S65C, isoladamente, não representam maior risco de sobrecarga de ferro, mesmo na condição de homozigose; entretanto, quando associadas à mutação C282Y ou a condições patológicas capazes de alterar o metabolismo do ferro, como talassemia beta ou alfa, e esferocitose hereditária, podem desempenhar papel importante na predisposição ao acúmulo patológico de ferro no organismo. ${ }^{(1,5,13-18)}$

Cançado et al., estudando as principais mutações do gene HFE em pacientes com sobrecarga de ferro (maioria dos pacientes com ferritina sérica (FS) $>1000 \mathrm{ng} / \mathrm{mL}$ e com sintomas e sinais secundários ao excesso de ferro), observaram frequência alélica de $76 \%$ (38/50), sendo que 30\% eram homozigotos para a mutação C282Y (Tabela 1). Além disso, demonstraram que os índices de saturação da transferrina (ST) e FS eram significativamente maiores nos doentes homozigotos para a mutação $\mathrm{C} 282 \mathrm{Y}$, confirmando tanto a correlação entre o genótipo $\mathrm{C} 282 \mathrm{Y} / \mathrm{C} 282 \mathrm{Y}$ e maior risco de sobrecarga de ferro, como também o fato de que a anemia hemolítica crônica, a hepatite $\mathrm{C}$ e o consumo excessivo de bebida alcoólica contribuem para o aumento dos estoques de ferro do organismo e constituem fatores de risco adicionais para a condição de sobrecarga de ferro em doentes com mutação do gene HFE. ${ }^{(19)}$

$\mathrm{O}$ grupo francês que estuda a $\mathrm{HH}$, liderado pelo professor Pierre Brissot, propôs a divisão dos indivíduos C282Y/ C282Y em cinco estágios, de acordo com dados laboratoriais e clínicos: estágio 0 , apenas genótipo $\mathrm{C} 282 \mathrm{Y} / \mathrm{C} 282 \mathrm{Y}$; estágio 1, genótipo C282Y/C282Y e ST > 45\%; estágio 2, genótipo $\mathrm{C} 282 \mathrm{Y} / \mathrm{C} 282 \mathrm{Y}, \mathrm{ST}>45 \% \mathrm{e} \mathrm{FS} \geq 300 \mathrm{ng} / \mathrm{mL} \geq 200 \mathrm{ng} / \mathrm{mL}$ para homens e mulheres, respectivamente; estágio 3 , alterações do estágio 2 e presença de manifestações clínicas como 
astenia, fadiga, impotência; estágio 4, alterações do estágio 3 associadas a complicações clínicas graves como cirrose hepática, miocardiopatia e diabetes melito insulino-dependente. Os estágios de 0 a 2 correspondem à fase pré-clínica, e os estágios 3 e 4, à fase clínica. Estima-se que 50\% dos indivíduos $\mathrm{C} 282 \mathrm{Y} / \mathrm{C} 282 \mathrm{Y}$ encontram-se no estágio 2, 25\% no estágio 3 e menos de $10 \%$ no estágio $4 .^{(4)}$

\section{Fisiopatologia}

Os doentes com HH têm aumentado o ritmo da absorção intestinal de ferro, podendo atingir $10 \mathrm{mg} /$ dia ou mais. Atualmente, a hepcedina é considerada a principal proteína responsável pela regulação de ferro do organismo; ela é sintetizada no fígado e sua produção é estimulada pelo aumento dos depósitos de ferro, lipopolissacarídeos e pela interleucina-6, mas é inibida em decorrência de anemia, hipóxia tecidual, eritropoese ineficaz (devido à síntese da proteína GDF-15) e alcoolismo. A hepcedina, ligando-se à ferroportina - principal proteína exportadora de ferro, localizada na membrana basolateral dos enterócitos, macrófagos e eritrócitos -, promove sua internalização e degradação, inibindo a absorção intestinal de ferro e diminuindo a liberação, para o plasma, do ferro presente nos macrófagos. ${ }^{(1,2)}$

Nos pacientes com HH (tipos 1, 2 e 3), há redução da síntese de hepcedina, fato que ocasiona o aumento da absorção intestinal de ferro e da liberação de ferro dos macrófagos, levando ao seu acúmulo progressivo e patológico no organismo. ${ }^{(1,2)}$

A toxicidade do ferro está relacionada ao ferro livre, ou seja, àquele não ligado à transferrina. A partir do momento no qual a quantidade plasmática de ferro ultrapassa a capacidade de saturação da transferrina, a concentração de ferro livre não ligado à transferrina (NTBI, non-transferrin-bound iron), mais especificamente a fração redoxi-ativa denominada LPI (labile plasma iron), aumenta, ocasionando lesão celular, uma vez que sua capacidade de penetrar nas células dá-se mais fácil e rapidamente que o ferro ligado à transferrina. ${ }^{(1-3)}$

O ferro livre atua como catalizador de reações oxidativas e consequente síntese de radicais superóxidos e radicais hidroxilas livres; a conversão do superóxido em $\mathrm{H}_{2} \mathrm{O}_{2}$ pela superóxido dismutase causa a peroxidação de lípides da membrana de diversas organelas citoplasmáticas, como as mitocôndrias e os microssomos, com consequente dano celular, fibrose reativa, esclerose e insuficiência funcional. $^{(1-3)}$

Nos doentes com HH, observa-se o aumento da expressão do gene do colágeno, com consequente aumento da sua produção no interior dos lipócitos hepáticos, que, progressivamente, são substituídos por fibrose. A coexistência de fatores como consumo excessivo de bebida alcoólica e hepatopatia crônica pelo vírus $\mathrm{C}$ da hepatite agrava e acelera ainda mais o processo. ${ }^{(1-5)}$

\section{Manifestações clínicas}

O quadro clínico da HH é bastante variável, insidioso e dependente do acúmulo de ferro, que ocorre lenta e progressivamente por várias décadas. A maioria dos doentes tornase sintomática entre a $3^{\mathrm{a}}$ e a $5^{\mathrm{a}}$ décadas de vida, sendo que, nas mulheres, as manifestações clínicas são observadas cinco a dez anos mais tarde do que nos homens, devido à lactação e às perdas sanguíneas fisiológicas que ocorrem no período menstrual. ${ }^{(1,13-18)}$

Os sintomas mais referidos são: fadiga (de 70\% a 80\%), artralgia/artrite (de $40 \%$ a 50\%), dor abdominal (de 20\% a $60 \%$ ), diminuição da libido ou impotência sexual (de 20\% a $50 \%$ ), perda de peso (de $10 \%$ a $50 \%$ ); os sinais clínicos mais frequentes para o diagnóstico são: hepatomegalia (de 50\% a $90 \%$ ), hiperpigmentação da pele (de $30 \%$ a $80 \%$ ), hipogonadismo (de $20 \%$ a $50 \%$ ), artropatia, esplenomegalia, diabetes melito, cirrose hepática, miocardiopatia e/ou arritmia. ${ }^{(1,13-18)}$

O risco de carcinoma hepático é cerca de vinte vezes maior nos pacientes com $\mathrm{HH}$ e é mais frequente em pacientes com cirrose hepática. ${ }^{(5,20)}$

\section{Diagnóstico}

O diagnóstico da $\mathrm{HH}$ compreende tanto a avaliação e a confirmação laboratorial da sobrecarga de ferro como a pesquisa das mutações do gene HFE (C282Y, H63D e S65C). Duas dosagens consecutivas de ST, com valores acima de $45 \%$ para ambos os gêneros, e da FS acima de $200 \mathrm{ng} / \mathrm{ml}$ nas mulheres e $300 \mathrm{ng} / \mathrm{ml}$ nos homens, e a presença em homozigose da mutação C282Y - e, em alguns casos, C282Y/ H63D - confimam o diagnóstico..$^{(1,4,21)}$

A ST persistentemente elevada é o parâmetro laboratorial mais importante e precoce para o diagnóstico da $\mathrm{HH}$, e, usualmente, ela ocorre antes do aparecimento de sintomas e/ou sinais relacionados à sobrecarga de ferro. ${ }^{1,4}$

A FS, se constantemente elevada, está associada à presença de sintomas e sinais clínicos relacionados à sobrecarga de ferro. Dessa forma, a história clínica e o exame físico são fundamentais para a avaliação da presença e da intensidade dos possíveis sintomas e sinais, como, por exemplo, astenia crônica, impotência, artralgia, hiperpigmentação da pele, hepatomegalia, diabete, osteopenia, miocardiopatia; devem ser considerados, também, o sexo, a idade e o tipo de comprometimento (hepático ou extra-hepático). ${ }^{1,4}$

O diagnóstico de sobrecarga de ferro pode ser confirmado por meio da biópsia hepática, quando a análise qualitativa por método histoquímico, por meio da coloração do ferro não hemínico, com o azul da Prússia (Reação de Perls), detecta a presença de siderose hepática em grau III/IV; também pode ser por meio da análise quantitativa do conteúdo hepático de ferro, e para isso utiliza-se a espectroscopia de absorção atômica, ou a espectometria de massa, que demonstra 
valores superiores a $3 \mathrm{mg} / \mathrm{g}$ de tecido hepático seco. (1,4,20,22) $^{-1}$

Mais recentemente, o exame de Ressonância Nuclear Magnética (RNM) tornou-se um importante aliado para o diagnóstico da sobrecarga de ferro, porque é um método não invasivo que permite a quantificação indireta do conteúdo de ferro em diferentes órgãos; o método está validado tanto nos EUA quanto na Europa, sendo atualmente o exame preferencial para o diagnóstico e o acompanhamento de pacientes com sobrecarga de ferro transfusional. ${ }^{(4,20-24)}$

Apesar de ser um método invasivo, a biópsia hepática é precisa tanto para avaliar a intensidade e a extensão do processo inflamatório hepático como para detectar a presença de cirrose; por isso, esse procedimento é indicado para pacientes com sorologia reagente para vírus $\mathrm{B}$ ou $\mathrm{C}$ da hepatite e para indivíduos homozigotos para a mutação C282Y com mais de 40 anos e/ou alanina aminotransferase elevada e/ou FS > $1000 \mathrm{ng} / \mathrm{ml}$. Na ausência desses três fatores, o risco de fibrose hepática é mínimo, enquanto que, na presença de dois ou três, o risco é grande e esse quadro tem impacto no prognóstico do paciente. . $^{(20,23)}$

A constatação de sobrecarga de ferro em indivíduos sem mutação do gene HFE é pouco frequente; nesse caso, se o paciente tiver menos de 30 anos, é mais provável a existência de mutação no gene da hemojuvelina ou da hepcedina, tornando-se necessário, portanto, o estudo desses genes. Se o paciente tiver mais de 30 anos, é bastante provável que haja mutação no gene da ferroportina ou do receptor $_{2}$ da transferrina. ${ }^{(20-24)}$

É importante ressaltar que, independentemente de se confirmar o diagnóstico genotípico, a presença de sobrecarga já indica a necessidade de se iniciar o tratamento para a remoção do excesso de ferro. ${ }^{(4)}$

\section{Diagnóstico diferencial}

Em indivíduos obesos, ou que apresentam um quadro inflamatório, a ST pode parecer normal ou diminuída; por isso, nesses casos, a dosagem da proteína $\mathrm{C}$ reativa auxilia na confirmação de inflamação, caso ela esteja elevada. ${ }^{(4,23,24)}$

Também a FS pode estar elevada sem nenhuma relação com o aumento do depósito de ferro, e, nesse caso, a ST costuma estar normal; isso pode ser observado quando há doença inflamatória ou infecciosa, necrose hepatocelular, hepatites virais, alcoolismo, esteato-hepatite não alcoólica, síndrome metabólica e neoplasia..$^{(4,23-26)}$

A síndrome metabólica é uma das mais frequentes causas atuais de hiperferritinemia e caracteriza-se por obesidade, hipertensão arterial, diabetes não insulino-dependente, hiperlipidemia e hiperuricemia; portanto, é fundamental investigar e excluir outras causas de hiperferritinemia não relacionadas à $\mathrm{HH}$, sobretudo doença hepática e alcoolismo, que são muito mais frequentes que a própria HH. ${ }^{(23-26)}$

Há causas menos frequentes de hiperferritinemia e que não estão relacionadas à sobrecarga de ferro, como a síndrome da catarata-hiperferritina, a doença de Gaucher e a síndrome de ativação do macrófago. ${ }^{(25,26)}$

\section{Tratamento}

$\mathrm{O}$ tratamento do paciente com $\mathrm{HH}$ compreende a remoção do excesso de ferro do organismo por meio de flebotomia ou de sangria terapêutica; trata-se de um procedimento seguro, econômico e eficaz. . $^{(1,3,4,25)}$

O tratamento deve ser iniciado tão logo seja constatada a sobrecarga de ferro, preferencialmente ainda na fase assintomática da doença (estádio $\leq 2$ ), sobretudo antes do desenvolvimento de fibrose ou de cirrose hepática. ${ }^{(4,25)}$

Apesar do acúmulo de ferro, os pacientes com aceruloplasminemia e os portadores da doença da ferroportina $(\mathrm{HH}$ tipo 4A) geralmente apresentam anemia e não respondem satisfatoriamente, ou até não toleram, a flebotomia de repetição. $^{(4,25)}$

\section{Tratamento com flebotomia terapêutica}

O procedimento consiste na remoção de 450 a $500 \mathrm{~mL}$ de sangue, o que leva à retirada de $200 \mathrm{a} 250 \mathrm{mg}$ de ferro. Recomenda-se a realização de uma flebotomia semanal, embora o intervalo possa variar de acordo com a tolerabilidade do paciente ao procedimento. A duração do tratamento pode variar de semanas a meses, dependendo da quantidade de ferro em excesso e da tolerância do doente ao tratamento. ${ }^{(4,25)}$

As sangrias devem ser mantidas até a obtenção da depleção do ferro, o que geralmente ocorre quando há o aparecimento de anemia microcítica $(\mathrm{Hb} \pm 11 \mathrm{~g} / \mathrm{dL}$ e volume corpuscular médio menor que $75 \mathrm{fL}$ ), a FS é menor que $25 \mathrm{ng} /$ $\mathrm{mL}$ e a ST é menor que $40 \%{ }^{(4,25)}$

A partir desse quadro, a concentração da $\mathrm{Hb}$ circulante precisa ser mantida dentro dos valores de normalidade, e a flebotomia deve ser realizada em intervalos apropriados, a fim de se manterem os valores de FS entre 100 e $200 \mathrm{ng} / \mathrm{mL}$, e os de ST entre $20 \%$ e $30 \%$. Para isso, recomenda-se, em média, a realização anual de quatro a seis sangrias nos homens, e de duas a quatro nas mulheres, embora alguns indivíduos possam requerer um número maior do procedimento. ${ }^{(4,25)}$

$\mathrm{O}$ controle dos pacientes submetidos à flebotomia deve ser feito por meio de um hemograma, sempre antes de cada procedimento e por meio da dosagem da FS e da ST após três ou quatro sangrias. ${ }^{(4,25)}$

\section{Eritrocitaférese associada à eritropoetina}

Embora seja um esquema terapêutico pouco estudado, a eficácia da associação de eritrocitaférese e eritropoetina (150 U/Kg/semana) para a remoção rápida do excesso de ferro está comprovada, e, por isso, embora mais complexo e de custo mais elevado, pode ser considerado uma opção para 
pacientes com complicações graves, que requerem tratamento mais intensivo. ${ }^{(27)}$

\section{Orientação nutricional}

Quanto à orientação dietética dos pacientes com $\mathrm{HH}$, recomenda-se evitar a ingestão de compostos à base de ferro e de vitamina $\mathrm{C}$, abster-se de bebidas alcoólicas, abster-se de manusear ou ingerir frutos do mar ou peixes marinhos crus, devido ao risco de infecção - às vezes, fatal - pelo Vibrio vulnificus e pela Salmonella enteritidis. ${ }^{(1,4)}$

\section{Resultados esperados pós-flebotomia}

Os resultados mais observados nos pacientes submetidos à flebotomia de repetição são: melhora da astenia; hiperpigmentação da pele; alterações hepáticas e da função cardíaca; piora da artralgia nas primeiras flebotomias com melhora subsequente; controle mais fácil do diabetes melito e, em alguns casos, redução da dose necessária de insulina. Os pacientes que já apresentam cirrose hepática geralmente não obtêm nenhuma melhora do quadro clínico e, neles, o risco de carcinoma hepatocelular persiste, aumentado, não obstante o sucesso do tratamento. ${ }^{(4,24)}$

Para os doentes com anemia e/ou que não toleram ou recusam a remoção do excesso de ferro por meio da flebotomia, pode-se lançar mão do uso de quelante de ferro, como a desferroxamina subcutânea; mais recentemente, um novo quelante de ferro, denominado deferasirox, administrado por via oral e em uma única dose diária, foi aprovado para pacientes com sobrecarga de ferro transfusional; possivelmente será uma nova opção terapêutica para esse grupo específico de pacientes com $\mathrm{HH} .{ }^{(28)}$

\section{Prognóstico e mortalidade}

Os doentes com HH têm sobrevida menor se comparada com a de indivíduos da população geral para o mesmo sexo; entretanto, quando o diagnóstico precede o início do diabetes melito e o tratamento é instituído antes do desenvolvimento de cirrose hepática, a sobrevida dos doentes passa a ser semelhante à da população geral. As principais causas de morte nos doentes com HH não tratados são: insuficiência cardíaca e/ou arritmia, insuficiência hepatocelular e carcinoma hepático. ${ }^{(4,5,15,17,22)}$

\section{Conclusões}

A mutação do gene HFE indica a existência de alteração genética relacionada à $\mathrm{HH}$ e maior predisposição ao desenvolvimento do fenótipo da doença, mas não é suficiente para o diagnóstico de $\mathrm{HH}$.

A HH não é a causa mais frequente de hiperferritinemia. Para o diagnóstico de $\mathrm{HH}$, deve prevalecer não a expressão genotípica, mas a fenotípica, mais especificamente a constatação de sobrecarga de ferro e suas repercussões, laboratoriais e clínicas no organismo.

$\mathrm{O}$ diagnóstico precoce da $\mathrm{HH}$ e a pronta instituição do tratamento são capazes de prevenir o aparecimento de complicações orgânicas graves, e, mesmo nos indivíduos com algum grau de disfunção orgânica, podem reverter ou impedir sua progressão. $\mathrm{O}$ tratamento com flebotomias, se iniciado antes do desenvolvimento da cirrose hepática, confere aos pacientes com HH sobrevida semelhante à dos indivíduos da população geral.

\section{Abstract}

Hereditary hemochromatosis refers to several inherited disorders of the iron metabolism that lead to tissue iron overload. Classical hereditary hemochromatosis is associated with mutations of the HFE gene (C282Y homozygotes or C282Y/H63D compound heterozygotes) and is almost exclusively found in populations of northern European descent. Non-HFE-associated hereditary hemochromatosis is caused by mutations in other recently identified genes involved in the iron metabolism. Hepcidin is an iron regulatory hormone that inhibits ferroportin-mediated iron export from enterocytes and macrophages. Defective hepcidin gene expression or function may underlie most forms of hereditary hemochromatosis. Target organs and tissues affected by hereditary hemochromatosis include the liver, heart, pancreas, joints, and skin, with cirrhosis and diabetes melittus representing late signs of disease in patients with very high liver iron concentrations. Patients with an established diagnosis of hereditary hemochromatosis and iron overload should be treated with phlebotomy to achieve body iron depletion followed by maintenance phlebotomy. The most frequent causes of death in hereditary hemochromatosis are liver cancer, cirrhosis, cardiomyopathy, and diabetes. However, patients who undergo successful iron depletion before developing cirrhosis or diabetes can have normal life expectancy.

Keywords: Iron deficiency/ metabolism; Iron overload; Hemochromatosis/genetics; Hemocromatosis/congenital; Phlebotomy

\section{Referências}

1. Pietrangelo A. Hereditary hemochromatosis - a new look at an old disease. N Engl J Med. 2004;350(23):2383-9.

2. Andrews NC.Forging a field: the golden age of iron biology. Blood. 2008;112(2):219-30.

3. Fix OK, Kowdley KV. Hereditary hemochromatosis. Minerva Med. 2008;99(6):605-17.

4. Brissot P, de Bels F. Current approaches to the management of hemochromatosis. Hematology Am Soc Hematol Educ Program. 2006:36-41.

5. Pietrangelo A. Inherited metabolic disease of the liver. Curr Opin Gastroenterol. 2009;25(3):209-14.

6. Asberg A, Hveem K, Thorstensen K, Ellekjter E, Kannelønning K, Fjosne U, et al. Screening for hemochromatosis: high prevalence and low morbidity in an unselected population of 65,238 persons. Scand J Gastroenterol. 2001;36(10):1108-15. 
7. Adams PC, Reboussin DM, Barton JC, McLaren CE, Eckfeldt JH, McLaren GD, et al. Hemochromatosis and iron-overload screening in a racially diverse population. N Engl J Med. 2005; 352(17):1769-78.

8. Agostinho MF, Arruda VR, Basseres DS, Bordin S, Soares MC, Menezes RC, et al. Mutation analysis of the HFE gene in Brazilian populations. Blood Cells Mol Dis. 1999;25(5-6):324-7.

9. Calado RT, Franco RF, Pazin-Filho A, Simões MV, Marin-Neto JA, Zago MA. HFE gene mutations in coronary atherothrombotic disease. Braz J Med Biol Res. 2000;33(3):301-6.

10. Pereira AC, Mota GF, Krieger JE. Hemochromatosis gene variants in three different ethnic populations: effects of admixture for screening programs. Hum Biol. 2001;73(1):145-51.

11. Oliveira TM, Souza FP, Jardim AC, Cordeiro JA, Pinho JR, Sitnik $\mathrm{R}$ et al. Mutations in the HFE gene $(\mathrm{C} 282 \mathrm{Y}, \mathrm{H} 63 \mathrm{D}, \mathrm{S} 65 \mathrm{C})$ in a Brazilian population. Braz J Med Biol Res. 2006;39(12):1575-80.

12. Terada CT, Santos PC, Cançado RD, Rostelato S, Lopreato FR, Chiattone CS, et al. Iron deficiency and frequency of HFE C282Y gene mutation in Brazilian blood donors. Transfus Med. 2009; 19(5):245-51

13. Bulaj ZJ, Ajioka RS, Phillips JD, LaSalle BA, Jorde LB, Griffen $\mathrm{LM}$, et al. Disease-related conditions in relatives of patients with hemochromatosis. N Engl J Med. 2000;343(21):1529-35.

14. Wojcik JP, Speechley MR, Kertesz AE, Chakrabarti S, Adams PC, et al. Natural history of $\mathrm{C} 282 \mathrm{Y}$ homozygotes for hemochromatosis. Can J Gastroenterol. 2002;16(5):297-302.

15. Ajioka RS, Kushner JP. Clinical consequences of iron overload in hemochromatosis homozygotes. Blood. 2003;101(9):3351-3; discussion 3354-8.

16. Beutler E, Felitti VJ, Koziol JA, Ho NJ, Gelbart T, et al. Penetrance of $845 \mathrm{G}^{\circ} \mathrm{A}(\mathrm{C} 282 \mathrm{Y}) \mathrm{HFE}$ hereditary haemochromatosis mutation in the USA. Lancet. 2002;359(9302):211-8. Comment in: Lancet. 2002;360(9330):411-2; author reply 413-4, Lancet. 2002;360 (9330):412-3; author reply 413-4, Lancet. 2002;360(9330):412; discussion 413-4, Hepatology 2002;36(2):500-3, Lancet. 2005;366 (9482):269-71.

17. Allen KJ, Gurrin LC, Constantine CC, Osborne NJ, Delatycki MB, Nicoll AJ, et al. Iron-overload-related disease in HFE hereditary hemochromatosis. N Engl J Med. 2008;358(3):221-30.

18. Gurrin LC, Osborne NJ, Constantine CC, McLaren CE, English DR, Gertig DM, et al. The natural history of serum iron indices for HFE C282Y homozygosity associated with hereditary hemochromatosis. Gastroenterology. 2008;135(6):1945-52. Comment in: Gastroenterology. 2008;135(6):1855-7.

19. Cançado RD, Guglielmi AC, Vergueiro CS, Rolim EG, Figueiredo MS, Chiattone CS, et al. Analysis of HFE gene mutations and HLA-A alleles in Brazilian patients with iron overload. Sao Paulo Med J. 2006;124(2):55-60.

20. Deugnier Y, Brissot P, Loréal O. Iron and the liver: update 2008. J Hepatol. 2008;48 (Suppl 1):S113-23.

21. Beutler E. The HFE Cys282Tyr mutation as a necessary but not sufficient cause of clinical hereditary hemochromatosis. Blood. 2003;101(9):3347-50.

22. Pietrangelo A, Oude Elferink R, Prieto J, Bacon BR, et al. Genetics in liver diseases. J Hepatol. 2007;46(6):1143-8.

23. Deugnier YM, Loréal O, Turlin B, Guyader D, Jouanolle H, Moirand $\mathrm{R}$, et al. Liver pathology in genetic hemochromatosis: a review of 135 homozygous cases and their bioclinical correlations. Gastroenterology. 1992;102(6):2050-9.

24. Brissot P, Troadec MB, Bardou-Jacquet E, Le Lan C, Jouanolle AM, Deugnier Y, et al. Current approach to hemochromatosis. Blood Rev. 2008;22(4):195-210.
25. Waalen J, Felitti VJ, Gelbart T, Beutler E. Screening for hemochromatosis by measuring ferritin levels: a more effective approach. Blood. 2008;111(7):3373-6.

26. Olynyk JK, Gan E, Tan T. Predicting iron overload in hyperferritinemia. Clin Gastroenterol Hepatol. 2009;7(3):359-62.

27. Mariani R, Pelucchi S, Perseghin P, Corengia C, Piperno A, et al. Erytrocytapheresis plus erythropoietin: an alternative therapy for selected patients with hemochromatosis and severe organ damage. Haematologica. 2005;90(5):717-8.

28. Cappellini MD, Cohen A, Piga A, Bejaoui M, Perrotta S, Agaoglu L, et al. A phase 3 study of deferasirox (ICL670), a once-daily oral iron chelator, in patients with beta-thalassemia. Blood. 2006; 107(9):3455-62. Comment in: Blood. 2006;108(2):778, Blood. 2006;108(2):774-5; author reply 775-6, Blood. 2006; 108 (5): 1775-6; author reply 1776 . 